\title{
Intimate Partner Violence During Pregnancy and Neonatal Mortality in Eastern Ethiopia: A Population Based Matched Case- Control Study
}

\author{
Wondimye Ashenafi ( $\nabla$ wondtg@gmail.com ) \\ Haramaya University \\ Bezatu Mengistie \\ Haramaya University College of Health and Medical Sciences \\ Gudina Egata \\ Haramaya University College of Health and Medical Sciences \\ Yemane Berhane \\ Addis Continental Institute of Public Health
}

\section{Research article}

Keywords: intimate partner violence, partner controlling behavior, pregnancy, women, abuse, neonatal mortality, Ethiopia

Posted Date: August 18th, 2020

DOI: https://doi.org/10.21203/rs.3.rs-58851/v1

License: (1) This work is licensed under a Creative Commons Attribution 4.0 International License. Read Full License 


\section{Abstract}

Background: Intimate partner physical, sexual and psychological abuses and controlling behaviors against pregnant women are common in low-income settings. In Ethiopia, different forms of intimate partner violence (IPV) during pregnancy is highly prevalent and neonatal mortality has been one of the health indicators that did not show significant improvement in the country despite a significant reduction in under-five mortality. We aimed to examine whether exposure to different forms of IPV during pregnancy is associated with neonatal mortality.

Methods: A population based matched case-control study was conducted from January to October 2018 in Eastern Ethiopia. A sample of 103 cases (biological mothers of deceased neonates) and 412 controls (biological mothers of survived neonates) were included in the study. The cases and controls were matched for date of birth, sex of the newborn and place of residences.

Conditional logistic regression analysis was performed to assess association between IPV during pregnancy and neonatal mortality, controlling for selected potential confounders.

Results: After controlling for potential confounding factors (pregnancy and obstetric as well socio-demographic characteristics) sexual violence during pregnancy [Adjusted Odds Ratio $(A O R)=3.20: 95 \% \mathrm{Cl}: 1.09-9.33$ ] and husband/partner controlling behavior (AOR=2.42: 95\% Cl: 1.06-5.51) were found to be significantly associated with neonatal mortality. Psychological and physical violence during pregnancy did not show significant associations with the neonatal mortality.

Conclusion: Neonatal mortality is strongly associated with intimate partner sexual violence and controlling behaviors during pregnancy. Involving men in maternal health programs is imperative to address issues of violence in pregnancy and promote maternal well being and child health.

\section{Background}

The World Health Organization (WHO) defines intimate partner violence (IPV) against women as a behavior within an intimate relationship that causes physical, sexual and psychological harm including acts of physical aggression, sexual coercion, psychological abuse and controlling behaviors by current or former male intimate partner[1]. It is considered as a gross human rights violation[2] with lasting negative impact on women's health[3]. The impact is severe when it happens during pregnancy as the fetus and the newborn could also be affected negatively[4].

Intimate Partner Violence during Pregnancy (IPVP) is widely prevalent in Africa, particularly in Sub-Saharan Africa, with an estimate of $2.3-57.1 \%$ women in the region experiencing it anytime during their pregnancy period[5]. In Ethiopia, the prevalence of IPV during pregnancy generally varies between $4 \%$ and $58.7 \%[6,7]$. Wife beating, husband's controlling behaviors and marital forced sex are widely accepted and justified practices in the country due to the socio-cultural dynamics that put women in subordinate position relative to men[8, 9].

Neonatal mortality, death which occurs during the first 28 days of life, contributes to 2.5 million deaths globally, where the vast majority of these deaths (89\%) arises from low and lower-middle income countries[10]. Sub-Saharan Africa has the highest share of burden in neonatal mortality [11]. In Ethiopia, national estimate in neonatal mortality rate in 2016 was as high as 29 deaths per 1000 live births which accounts $60.4 \%$ of the infant mortality[7]. Despite a significant reduction of $60 \%$ in under-five mortality in the years between 2000 and 2016, a relatively lower rate of decrease in neonatal mortality was achieved (41\%) in the same time period [7]. Given this rate of decrease in neonatal mortality, it might be a big challenge to reach the target the country set to reduce a neonatal mortality rate of 10 per 1000 live births by end of 2020[12].

Available evidences suggest that IPV perpetrated during pregnancy could lead to elevated risks of neonatal death [13-16]. Different theoretical explanations have been provided on the pathways through which IPV during pregnancy lead to the increased risk of neonatal/newborn death. One pathway is that exposure to various forms of abuse during pregnancy is associated with poor maternal nutrition[4] and elevated maternal stress levels[17], both of which are linked with low infant birth weights[18-20], which when combined with poor neonatal nursing of the abused mothers[21] can contribute for increased risks of neonatal death[22, 23]. The other possible pathway is that women in abusive or controlled relationships might have limited household decision autonomy and use of $\mathrm{MCH}$ services[24] which could indirectly contribute to poor newborn health and survival [25, 26]. Chronic physical trauma, 
maternal sexual transmitted infections and pregnancy complications are also in a casual pathway between violence experienced during pregnancy and elevated risk of newborn deaths[17, 25].

Apart from IPV, socio-economic as well as obstetric and neonatal factors have been described by the Mosley and Chen conceptual framework on child survival[27]. Prior studies in Ethiopia documented risk factors such as young age at pregnancy or birth [28, 29], living in rural area [29] and no or lower level of educational or employment status [30,31], which all relate to availability and use of limited resources in taking care of children that would indirectly contribute to the neonatal survival. Pregnancy and obstetric factors such as poor utilization of ANC, PNC or immunizations [28, 32, 33]; high gravidity and parity[28, 30]; births occurring at home[32]; low birth weight $[28,32,33]$ and multiple (as opposed to singleton) form of deliveries [28, 33] have been extensively studied in the country. Moreover, maternal health risk related behaviors such as poor nutrition intake, alcohol abuse and smoking in pregnancy were also indicated as indirect risk factors for neonatal mortality [32, 34-36].

Despite recent evidences suggest association between deaths in newborns/neonates and experience of IPV during pregnancy in the developing world [15,37], and particularly in East Africa[38], evidence in this interlink are hugely lacking in Ethiopia. The aim of this study is, therefore, to examine the association of different forms of intimate partner abuse during pregnancy (i.e., physical, sexual and psychological violence and husband/partner controlling behavior) and neonatal mortality using a community based matched case-control study in the Eastern part of Ethiopia.

\section{Methods}

\section{Study settings and period}

The study was conducted in communities of Eastern Ethiopia living in town of Harar and Kersa district under Health and Demographic Surveillance System (HDSS), namely Kersa and Harar HDSS sites. The Kersa HDSS has 24 randomly selected Kebeles (smallest administrative unit in Ethiopia) with an estimated 127,000 inhabitants. The Harar HDSS has 12 Kebeles with an estimated 56,000 inhabitants. Trade and farming are the main sources of living in these communities and Khat (Catha edulis), stimulant green leaf, chewing is prevalent in the area [39]. According to the 2016 Ethiopian Demographic Health Survey, the rates of neonatal mortality for the regional states of Harari (where Harar town is located) and Oromia (where Kersa district is located) was 34/1000 and 37/1000 live births, respectively[7]. The study was conducted between January 2018 and October 2018.

\section{Study design and sample}

A community-based matched case-control study was conducted from January to October 2018. The study population for the study was currently partnered mothers in their sixth week of giving live births permanently residing in the study area. A mother was considered currently partnered if she was either living together with husband (formally married) or living together with the intimate partner in an informal marriage at least during the index pregnancy. Cases constituted biological mothers of the live born baby who later died before the age of 28 days of life. Controls were biological mothers of the live neonates at the end of the first 28 days of birth.

The sample size was determined using PS (power and sample size calculation) software version 3.1.2 for a matched case control study with the following assumptions. A survey of violence against women in Ethiopia documented prevalence of violence during pregnancy of 4\% [7], and thus we have assumed experience of violence during pregnancy in mothers with live born children to be $4 \%$. As no prior published study relating IPVP and neonatal mortality in Ethiopia, and based on earlier study in Egypt[40], we assumed a 3 times higher odds (OR) for neonatal mortality in those exposed to violence during pregnancy than not exposed to it. Thus, assuming IPVP among the controls to be $4 \%$, OR of 3, power of $80 \%$, a $5 \%$ significance level, a $4: 1$ control to case ratio; a correlation coefficient $(\Downarrow)$ for exposure between matched case and control being unknown and hence considering a 0.2 phi( () coefficient, as suggested by Dupont (p. 1166-67)[41], a minimum of 86 cases and 344 controls were required for the study. Adding $20 \%$ for possible nonresponse, we needed a total of 103 cases and 412 controls.

In the study, we employed the following procedures to identify the cases and controls. Initial census and subsequent three months interval house-to-house surveys were carried out to identify pregnant women using a standard pregnancy procedure as described by Assefa et al [42]. Then, for those women who were found pregnant in the screening, a follow up of the pregnancy status were carried out throughout the study period. Interviews were then administered for those women who had live births, but only when they reached 
in their sixth week of postpartum. In such a way, the required number of cases (103 dead neonates) was reported among sample of 3015 eligible women in their sixth week of postpartum during the study period. The details of sample recruitment and procedures have been described previously in [43]. Each case was matched with four controls by date of birth, sex of the newborn and area of residences.

\section{Data collection}

Face-to-face interviews were carried out using a structured questionnaire that consists of socio-demographic, obstetric history and experiences of violence related questions. The WHO multi-country study domestic violence tool which was translated to local languages of the study area was employed to elicit the necessary information on the IPV and related questions [44]. The instrument was pretested in a district outside the study area and necessary adjustments were made accordingly. In administrating data collection, secondary level education and above female data collectors were involved with training given to them using the WHO training guide [45]. The WHO field work manual [46] was adapted to be used as a quick reference in the field work. The Institutional Health Research Ethics Review Committee of Haramaya University, College of Health and Medical Sciences ethically cleared the study (IHRERC/153/2017, dated October 26/2017). Written informed consent was obtained from each participant before interview. Following the WHO ethical and safety recommendation for studies on VAW[47], the study was initially framed as women's health, family relationship and life experiences study. However, while in the consent acquisition, each woman was personally introduced to the specific nature of the study before the interview was conducted. Interviews were conducted in a private setting and voluntarily. To maintain confidentiality, no identifying information was recorded on questionnaires and a unique code was used to distinguish the questionnaires. Each study participant was also informed the purpose of the study and the risks and benefits of participating in the study.

\section{Variables and measurements}

\section{Outcome and main exposure variables}

Neonatal mortality is an outcome variable determined based on the woman's report of the death of her baby within 28 days of life. The women experience of different forms of IPVP (Psychological, Physical, Sexual violence and husband's controlling behaviors) were considered as main independent variables, and were assessed using the WHO multi-country study tool[44]. Our study population is comprised of mothers currently partnered with father of index child, so for the purpose of this study, "intimate partner" refers to the father of the respondent's index child.

The Psychological IPVP was measured by at least one positive response to the following four questions that asked whether the respondent's husband/partner had (1) insulted her or made her feel bad about herself; (2) humiliated or belittled her in front of others; (3) scared/intimidated her on purpose (4) threatened to hurt her or someone close to her. Sexual IPVP was measured by at least one positive response to the following three acts: (1) If the woman reported having been physically forced to have sexual intercourse when she did not want to; (2) when the woman had intercourse out of fear of the husband/partner; or (3) when she was forced to perform other sexual acts that she found degrading or humiliating.

An affirmative answer to any one of the following six behaviors constitutes physical IPVP: (1) pushing or throwing something at the woman; (2) slapping; (3) punching or hitting with a fist or something harmful; (4) kicking or dragging her; (5) choking or burning intentionally; or (6) threatening or attacking with weapon (a knife, gun). Based on the WHO violence severity scale, we labeled the violence act as moderate if husband/partner slapped the woman or throws something at her during the pregnancy (i.e. we labeled the physical violence as 'moderate' if only one or both of the first two items of the mentioned six physical violence acts happened to the woman). Whereas, experiencing any one of the other/the rest four acts (items 3 to 6 of the above mentioned physical violence) was labeled as 'severe' physical violence[44].

Controlling behavior of the husband/partner were assessed using the below seven questions asking whether the women's husband/partner: commonly attempted to restrict women's contact with her family, kept her from seeing her friends, insisted knowing where she was all the time, ignored her or treated her indifferently, expected her to seek permission for seeking health care for herself, constantly was suspicious that she was unfaithful, and got angry if she spoke with another man. If the women reported one or more of these acts happened during pregnancy, then they are considered experiencing controlling behavior from their husband/partner[44]. 


\section{Control variables}

Women's household empowerment was derived from women's household decision making autonomy and their belief/attitude towards wife beating [7]. Household decision making was determined based on the number of household decisions a woman made alone or jointly with her husband/partner about: (1) spending income; (2) obtaining health care for herself; (3) major household purchases; (4) purchases for daily household needs; (5) visit to family or relatives; The response options were: (a) respondent alone, (b) respondent and husband/partner, (c) husband/partner alone, (d) others/someone else. Each question was assigned a value of 1 if the response was (a) or (b), and 0 for (c) or (d). Attitude towards wife beating was measured as a composite index consisting of the following items: a husband/partner is justified in hitting or beating his wife if she (a) is unable to carry household chores (b) disobeys/argues with him (c) asks him about his extramarital affairs (d) is barren and (e) refuses to have sexual intercourse with him. Each item had a response of 'Yes' or 'No', and a value of ' 0 ' was given if the woman accepted/justified beating and ' 1 ' otherwise.

Social support was measured by the Oslo Social Support Scale (OSSS-3) which has a 3-item questions commonly used to assess social support level[ $[48,49]$. Women were asked to respond on (i) the number of people so close to them that they count on if they encounter great personal problems ('none', '1-2', '3-5' and 5+); (ii) the interest and concern people show them in what they do ('none', 'little', 'uncertain', 'some', and 'a lot') and (iii) how easily they get practical help from neighbors when they need it ('very difficult', 'difficult', 'possible', 'easy' and 'very easy'). The sum score of the scale ranges from 3 to 14 , and has been grouped in to three broad categories[50]: "poor social support" 3-8, "moderate social support" 9-11, and "strong social support" 12-14.

In line with the Mosley and Chen conceptual framework[27], different confounders that have been conceptually linked to neonatal survival, such as women's age at birth[51, 52], education level[30,31], working status[30], and alcohol consumption during index pregnancy[53] were also considered in this study. Moreover, obstetric and neonatal related variables such as utilization of antenatal and postnatal cares, number of previous pregnancies, parity, perceived weight of neonate at birth, place of birth and type of birth (singleton or multiple births) were considered as confounders in the association of IPVP and neonatal mortality [28, 30, 32, 34]. Mothers' perceived reports on the birth size of the baby were considered as the proxy indicator of birth weight, and were dichotomized as small and normal size babies [7, 54].

\section{Data management and analysis}

The data were double entered and cleaned using Epi-data Version 3.1 and analyzed using STATA version-14. A principal component analysis (PCA) was carried out in order to derive the women's empowerment index using each of the variables representing women's household decision-making autonomy and their belief in/attitude towards wife beating. The PCA yielded three categories of women's household empowerment: low, medium and high status.

Conditional logistic regression model was used to assess association between the different IPVP types (physical, sexual and psychological violence and controlling behaviors) and neonatal mortality, by considering socio-demographic and obstetrical/ pregnancy related confounders. To examine the influence of IPVP on the odds of neonatal mortality, we ran series of adjusted multivariable models; one for each type of IPVP to assess the separate effects of the different forms of IPVP (Models IIV), and one full model (Final model) for all the types of IPVP together, in order to examine the effects of each type of IPVP controlling for the other. Each model also included the confounding variables described above.

Variables with $p$-value $\leq 0.25$ in the bivariate analysis were first considered for multivariable analysis; however, known confounders such as education of women and their parity that deemed to be considered were also included in the multivariable model though they did not reach $p$-value $\leq 0.25$. A p value $<0.05$ was used to declare the level of statistical significance in the multivariable analysis and adjusted odds ratios (AOR) along with $95 \%$ Cls were estimated. The Log-likelihood ratio test was used to select the final model. Pearson Chi-square and Hosmer-Lemeshow goodness-of-fit tests were used to test for model fitness. The explanatory variables were tested for multi-collinearity before entering to multivariable models using Variance Inflation Factor (VIF) of less than 10 values.

\section{Results}

\section{Profile of respondents (cases and controls)}


A total of 103 cases and 412 controls were included in the study. Most of the cases $(70.9 \%)$ and the controls $(75.8 \%)$ were $20-$ 34 years of age. Very few of the cases $(2.0 \%)$ and controls $(2.7 \%)$ had tertiary level education. More cases than the controls had seven or more previous pregnancies $(20.4 \%$ vs. $16.0 \%)$, had no attendance for ANC $(70.0 \%$ vs. $55.8 \%)$, gave births that were multiple $(12.6 \%$ vs. $1.7 \%)$ and small in size (22.3\% vs. $6.8 \%)$ [Table 1$]$.

Table 1

Characteristics of Participants (Cases and Controls), Eastern Ethiopia, 2018

\begin{tabular}{|c|c|c|c|c|}
\hline \multirow[t]{2}{*}{ Variable } & \multirow[t]{2}{*}{ Category } & \multicolumn{2}{|l|}{ Participants } & \multirow[t]{2}{*}{$P$ value } \\
\hline & & Cases, No (\%) [n= 103] & Controls, No (\%) [n= 412] & \\
\hline \multirow[t]{3}{*}{ Mother age(years) } & 19 or less & 14(13.6) & $41(9.9)$ & 0.505 \\
\hline & $20-34$ & 73(70.9) & $312(75.8)$ & \\
\hline & $35+$ & $16(15.5)$ & $59(14.3)$ & \\
\hline \multirow[t]{3}{*}{ Education level } & No formal education & $70(68.0)$ & $286(69.4)$ & 0.845 \\
\hline & Primary/Sec educ. & $31(30.0)$ & $115(27.9)$ & \\
\hline & Tertiary education & $2(2.0)$ & $11(2.7)$ & \\
\hline \multirow[t]{2}{*}{ ANC attendance } & Not attended & $69(70.0)$ & $230(55.8)$ & 0.040 \\
\hline & Attended 1+ & $34(33.0)$ & $182(44.2)$ & \\
\hline \multirow[t]{2}{*}{ PNC follow up } & Yes & 13(12.6) & $30(7.3)$ & 0.080 \\
\hline & No & $90(87.4)$ & $382(92.7)$ & \\
\hline \multirow[t]{2}{*}{ Birth Type } & Multiple & $13(12.6)$ & $7(1.7)$ & $<0.001$ \\
\hline & Singleton & $90(87.4)$ & 405(98.3) & \\
\hline \multirow[t]{2}{*}{ Birth place } & Health institution & $47(45.6)$ & 139(33.7) & 0.025 \\
\hline & Home & $56(54.4)$ & $273(66.3)$ & \\
\hline \multirow[t]{2}{*}{ Size at birth } & Normal size & $80(77.7)$ & $384(93.2)$ & $<0.001$ \\
\hline & Small size & $23(22.3)$ & $28(6.8)$ & \\
\hline \multirow[t]{3}{*}{ Gravidity } & $\leq 3$ & $58(56.3)$ & $219(53.2)$ & 0.263 \\
\hline & $4-6$ & $24(23.3)$ & $127(30.8)$ & \\
\hline & $7+$ & $21(20.4)$ & $66(16.0)$ & \\
\hline \multirow[t]{2}{*}{ Parity } & Primiparous & $24(23.3)$ & $84(20.4)$ & 0.516 \\
\hline & Multiparous & $79(76.7)$ & $328(79.6)$ & \\
\hline
\end{tabular}

\section{IPVP among cases and controls}

Twenty-five (24.3\%) of the cases and $132(32.0 \%)$ of the controls experienced any IPVP. Higher proportion of cases (20\%) than the controls (12.9\%) experienced all forms of IPVP at the same time (i.e., psychological, physical and sexual IPVP). Cases had more experience of psychological violence in isolation as compared to controls ( $44 \%$ vs. $39.4 \%)$, however, controls showed relatively more isolated experiences of the physical and the sexual violence as compared to the cases. Cases and controls were comparable in terms of co-occurrence in two possible violence combinations; psychological and physical (20\% vs. $20.4 \%)$, psychological and sexual $(8.0 \%$ vs. $8.3 \%)$ and physical and sexual (0\% vs. $0.7 \%)$ [Figure 1$]$.

\section{Results of conditional logistic regression}


Model I-IV demonstrates that sexual IPVP and husband's controlling behavior were significantly associated with neonatal mortality. In the joint model (the final full model), the odds of having neonatal mortality was more than three times higher ( $\mathrm{AOR}=3.20$ : $95 \% \mathrm{Cl}$ : 1.09-9.33) among mothers exposed to sexual IPV during pregnancy. Moreover, mothers who were controlled by their husbands had a more than two fold increase in the odds of having neonatal mortality ( $\mathrm{AOR}=2.42$ : $95 \% \mathrm{Cl}: 1.06-5.51)$ compared to the noncontrolled mothers (Table 2). Psychological and physical IPV during pregnancy did not show significant association with the neonatal mortality. 
Table 2

Results of conditional logistic regression on risk factors of Neonatal Mortality, Eastern Ethiopia, 2018

\begin{tabular}{|c|c|c|c|c|c|c|}
\hline \multirow[t]{2}{*}{ Variable } & \multirow[t]{2}{*}{ Category } & Model-I & Model-II & Model-III & Model-IV & Final-Model \\
\hline & & AOR(95\%Cl) & AOR(95\%Cl) & AOR(95\%Cl) & AOR(95\%Cl) & AOR(95\%Cl) \\
\hline \multirow{3}{*}{$\begin{array}{l}\text { Psychological } \\
\text { IPVP }\end{array}$} & No & 1 & & & & 1 \\
\hline & & & & & & \\
\hline & Yes & $1.18(0.60,2.32)$ & & & & $0.87(0.38,1.96)$ \\
\hline \multirow[t]{3}{*}{ Physical IPVP } & No & & 1 & & & 1 \\
\hline & $\begin{array}{l}\text { Yes, } \\
\text { moderate }\end{array}$ & & $1.17(0.41,3.29)$ & & & $0.96(0.28,3.16)$ \\
\hline & Yes, severe & & $1.30(0.23,7.24)$ & & & $0.99(0.12,7.95)$ \\
\hline \multirow[t]{2}{*}{ Sexual IPVP } & No & & & 1 & & 1 \\
\hline & Yes & & & $2.98(1.05,8.43)^{\star}$ & & $3.20(1.09,9.33)^{\star}$ \\
\hline \multirow{2}{*}{$\begin{array}{l}\text { Controlling } \\
\text { behaviors }\end{array}$} & No & & & & 1 & 1 \\
\hline & Yes & & & & $2.36(1.06,5.24)^{\star}$ & ${ }_{\star}^{2.42(1.06,5.51)}$ \\
\hline \multirow{3}{*}{$\begin{array}{l}\text { Age } \\
\text { group(years) }\end{array}$} & $<20$ & 1 & 1 & 1 & 1 & 1 \\
\hline & $20-34$ & $1.04(0.43,2.51)$ & $1.02(0.42,2.47)$ & $1.01(0.43,2.40)$ & $0.94(0.37,2.39)$ & $0.92(0.37,2.30)$ \\
\hline & $\geq 35$ & $0.84(0.17,3.90)$ & $0.80(0.16,3.82)$ & $0.73(0.15,3.54)$ & $0.81(0.17,3.95)$ & $0.70(0.14,3.65)$ \\
\hline \multirow[t]{3}{*}{ Education } & $\begin{array}{l}\text { No } \\
\text { education }\end{array}$ & 1 & 1 & 1 & 1 & 1 \\
\hline & Primary/sec. & $0.87(0.38,2.01)$ & $0.87(0.38,1.99)$ & $0.94(0.42,2.13)$ & $0.85(0.37,1.90)$ & $0.92(0.42,2.02)$ \\
\hline & Tertiary & $0.53(0.05,5.15)$ & $0.62(0.05,5.05)$ & $0.71(0.08,6.38)$ & $0.50(0.05,5.04)$ & $0.70(0.07,6.86)$ \\
\hline \multirow{3}{*}{$\begin{array}{l}\text { Education } \\
\text { (partner) }\end{array}$} & No & 1 & 1 & 1 & 1 & 1 \\
\hline & Primary/sec. & $1.39(0.73,2.67)$ & $1.41(0.74,2.69)$ & $1.53(0.79,2.93)$ & $1.38(0.72,2.64)$ & $1.50(0.77,2.93)$ \\
\hline & Tertiary & $1.91(0.40,9.04)$ & $1.94(0.39,9.46)$ & $1.93(0.41,9.00)$ & $1.99(0.44,9.09)$ & $2.07(0.44,9.72)$ \\
\hline \multirow{3}{*}{$\begin{array}{l}\text { Number of U5 } \\
\text { Children }\end{array}$} & $<2$ & 1 & 1 & 1 & 1 & 1 \\
\hline & & & & & & \\
\hline & $\geq 2$ & $0.06(0.03,0.14)^{*}$ & $0.07(0.03,0.14)^{\star}$ & $0.06(0.02,0.13)^{\star}$ & $0.06(0.03,0.13)^{*}$ & $0.05(0.02,0.12) *$ \\
\hline \multirow{2}{*}{$\begin{array}{l}\text { Working } \\
\text { status }\end{array}$} & Housewife & 1 & 1 & 1 & 1 & 1 \\
\hline & Working & $1.16(0.34,3.95)$ & $1.20(0.38,3.79)$ & $1.03(0.31,3.33)$ & $1.16(0.35,3.78)$ & $1.04(0.31,3.46)$ \\
\hline \multirow{2}{*}{$\begin{array}{l}\text { Working } \\
\text { status } \\
\text { (partner) }\end{array}$} & Not working & 1 & 1 & 1 & 1 & 1 \\
\hline & Working & $1.19(0.50,2.86)$ & $1.19(0.52,2.70)$ & $1.22(0.53,2.81)$ & $1.37(0.57,3.29)$ & $1.44(0.59,3.47)$ \\
\hline $\begin{array}{l}\text { Empowerment } \\
\text { Status }\end{array}$ & Low & 1 & 1 & 1 & 1 & 1 \\
\hline
\end{tabular}




\begin{tabular}{|c|c|c|c|c|c|c|}
\hline \multirow[t]{2}{*}{ Variable } & \multirow[t]{2}{*}{ Category } & \multirow{2}{*}{$\begin{array}{l}\text { Model-I } \\
\text { AOR(95\% Cl) }\end{array}$} & \multirow{2}{*}{$\begin{array}{l}\text { Model-II } \\
\text { AOR(95\%Cl) }\end{array}$} & \multirow{2}{*}{$\begin{array}{l}\text { Model-III } \\
\text { AOR(95\%Cl) }\end{array}$} & \multirow{2}{*}{$\begin{array}{l}\text { Model-IV } \\
\text { AOR(95\%Cl) }\end{array}$} & \multirow{2}{*}{$\begin{array}{l}\text { Final-Model } \\
\text { AOR(95\%Cl) }\end{array}$} \\
\hline & & & & & & \\
\hline & Medium & $0.62(0.31,1.22)$ & $0.61(0.31,1.22)$ & $0.59(0.30,1.14)$ & $0.50(0.23,1.06)$ & $0.47(0.22,1.02)$ \\
\hline & High & $0.46(0.20,1.08)$ & $0.46(0.19,1.07)$ & $0.43(0.18,1.03)$ & $0.38(0.15,0.90)^{*}$ & $0.35(0.13,0.90) *$ \\
\hline \multirow{4}{*}{$\begin{array}{l}\text { Social support } \\
\text { Status }\end{array}$} & Poor & 1 & 1 & 1 & 1 & 1 \\
\hline & & & & & & \\
\hline & Moderate & $1.64(0.61,4.37)$ & $1.66(0.60,4.60)$ & $2.00(0.69,5.81)$ & $1.96(0.68,5.69)$ & $2.43(0.76,7.75)$ \\
\hline & Strong & $1.02(0.40,2.56)$ & $1.03(0.41,2.59)$ & $1.03(0.40,2.66)$ & $1.19(0.46,3.10)$ & $1.20(0.44,3.25)$ \\
\hline \multirow[t]{2}{*}{ Alcohol Intake } & No & 1 & 1 & 1 & 1 & 1 \\
\hline & Yes & $0.71(0.14,3.49)$ & $0.71(0.14,3.72)$ & $0.51(0.13,1.96)$ & $0.84(0.17,4.24)$ & $0.58(0.16,2.12)$ \\
\hline \multirow{2}{*}{$\begin{array}{l}\text { ANC } \\
\text { attendance }\end{array}$} & Not attend & 1 & 1 & 1 & 1 & 1 \\
\hline & $\begin{array}{l}\text { Attended } \geq \\
1\end{array}$ & $0.42(0.20,0.87)^{\star}$ & $0.42(0.20,0.88)^{\star}$ & $0.42(0.20,0.83)^{\star}$ & $0.34(0.15,0.74)^{*}$ & $0.33(0.15,0.73) *$ \\
\hline \multirow[t]{2}{*}{ PNC follow up } & Yes & 1 & 1 & 1 & 1 & 1 \\
\hline & No & $0.39(0.10,1.43)$ & $0.40(0.10,1.52)$ & $0.34(0.09,1.24)$ & $0.32(0.07,1.36)$ & $0.27(0.06,1.08)$ \\
\hline \multirow[t]{2}{*}{ Birth Type } & Multiple & 1 & 1 & 1 & 1 & 1 \\
\hline & Single & $0.11(0.01,0.71)^{*}$ & $0.12(0.01,0.80)^{\star}$ & $0.11(0.02,0.74)^{\star}$ & $0.08(0.01,0.54)^{\star}$ & $0.07(0.01,0.47)$ * \\
\hline \multirow[t]{2}{*}{ Birth Place } & Facility & 1 & 1 & 1 & 1 & 1 \\
\hline & Home & $0.77(0.36,1.60)$ & $0.77(0.36,1.62)$ & $0.77(0.36,1.64)$ & $0.71(0.35,1.45)$ & $0.71(0.34,1.49)$ \\
\hline \multirow[t]{2}{*}{ Birth size } & Normal size & 1 & 1 & 1 & 1 & 1 \\
\hline & Small size & $1.87(0.78,4.46)$ & $1.86(0.78,4.41)$ & $1.89(0.75,4.76)$ & $1.85(0.77,4.47)$ & $1.87(0.75,4.71)$ \\
\hline \multirow[t]{3}{*}{ Gravidity } & $\leq 3$ & 1 & 1 & 1 & 1 & 1 \\
\hline & $4-6$ & $1.13(0.54,2.36)$ & $1.13(0.54,2.38)$ & $1.26(0.59,2.70)$ & $1.14(0.52,2.47)$ & $1.27(0.56,2.85)$ \\
\hline & $\geq 7$ & $1.91(0.67,5.41)$ & $1.98(0.69,5.68)$ & $2.25(0.76,6 . .66)$ & $2.15(0.76,6.11)$ & $2.49(0.82,7.52)$ \\
\hline \multirow[t]{2}{*}{ Parity } & Primiparous & 1 & 1 & 1 & 1 & 1 \\
\hline & Multiparous & $2.86(1.41,5.81)^{\star}$ & $2.87(1.39,5.91)^{\star}$ & $2.78(1.37,5.65)^{\star}$ & $3.61(1.69,7.69)^{\star}$ & $3.59(1.68,7.66) *$ \\
\hline $\begin{array}{l}\text { Early Initiation } \\
\text { of }\end{array}$ & No & 1 & 1 & 1 & 1 & 1 \\
\hline \multicolumn{7}{|l|}{ Breastfeeding } \\
\hline & Yes & $2.01(0.98,4.42)$ & $2.10(0.97,4.46)$ & $2.06(0.96,4.41)$ & $2.20(1.00,4.76)$ & $2.19(0.98,4.80)$ \\
\hline
\end{tabular}

From the rest of the control variables modeled together in the multivariable analysis, having level of women empowerment that was high (APR $=0.35 ; 95 \% \mathrm{Cl}: 0.13-0.90)$, more number of under five $(\geq 2)$ children(APR $=0.05 ; 95 \% \mathrm{Cl}: 0.02-0.12)$, attending ANC (APR = $0.33 ; 95 \% \mathrm{Cl}: 0.15-0.73)$ and having a singleton birth (APR $=0.07 ; 95 \% \mathrm{Cl}: 0.01-0.47)$ were associated with decreased odds of neonatal mortality. Being multiparous (APR $=3.59 ; 95 \% \mathrm{Cl}$ : 1.68-7.66) was associated with higher odds of neonatal mortality (Table 2).

\section{Discussion}


Our study aimed to assess whether any association exists between death of neonates and the mothers' experience of different forms of intimate partner violence while pregnant. We employed matched case control design in a population-based sample of postpartum mothers. Mothers who reported partner's controlling behavior and sexual abuse during pregnancy showed strong association with neonatal mortality. There was no association between psychological and physical IPVP with neonatal mortality.

In this study, the more than threefold increase of neonatal mortality for women experiencing sexual IPV during pregnancy (AOR = 3.20: 95\% Cl: 1.09-9.33) is in agreement with study findings from southern India [55, 56], some East African countries [16] and Norway[57]. The possible explanation for this association could be sexual violence in form of forceful sex in pregnancy might cause chronic stress[17] contributing to low birth weight delivery[18, 20], which might in turn increase the risk of death to the neonate [22, 23]. Sexual IPV is known to strongly associate with stressful and fearful living [57, 58].

Women who had controlling partners were more than twice as likely report deaths of their neonates $(\mathrm{AOR}=2.42: 95 \% \mathrm{Cl}: 1.06-5.51)$ than women with no controlling partners. A similar association has been found in a previous study where partner controlling behavior was related to a number of poor neonatal outcomes, including neonatal death [59]. It is evident that controlling partner's restriction of women's movement might make women disadvantaged in terms of utilizing maternal and child health (MCH) services such as ante or postnatal cares and immunizations[24], which have short or long term sequel on newborn survival[15, 25, 56]. The findings from present study showing significant proportion of women receiving no or limited support from significant others might also be indicative of partners controlling of the women's movement and contact.

Evidences in the association of different types of IPV during pregnancy and neonatal mortality are generally inconclusive, with some studies reporting positive association, and other studies found no association. Similar to our finding, for instance, a study from Malawi revealed no significant association between maternal exposure to physical IPV and neonatal mortality[60]. On the other hand, unlike our finding, a significant effect of physical and/or psychological IPVP on neonatal mortality was noted in studies done in low income settings in India[52] and Egypt[40]. The discrepancy in the findings of these two studies with our results might be that compared to our study both of the studies considered larger sample of women $(n>1800)$ which might powered the studies to detect the differences and in estimating the association.

Although our main interest is exploring association of IPVP with neonatal mortality, this study also found some factors that significantly influenced the survival of neonates. The women's attendance of ANC significantly associated with decreasing odds of neonate death is in agreement with studies conducted elsewhere [61, 62], which might indicate that ANC attendance contributed awareness on maternal nutrition and early detection of newborn danger signs. Multiple births associated with neonatal mortality in this study might be explained with fact that multiple births are usually small size births and are highly susceptible for different infections largely due to immature immune systems [63], which might lead to neonate deaths. Multiparous women having higher odds of death for their neonate in this study might suggest large number of children for the woman which is known to deplete maternal nutrition[64] and influence the newborn survival. Consistent with other studies[65,66], women's high empowerment status was significantly associated with neonatal mortality. It is evident that when mothers are more empowered, they are likely to be more educated and have better knowledge about healthcare behavior for themselves and their children, which might contribute for low risk of neonate death[23].

The consideration of severity of violence is one merit/strength of this study that can be considered provide additional information on the condition of abuse experiences and the related neonatal mortality. Moreover, as the recall period is very short, possibility of recall bias due to differential recall of information among mothers of deceased neonates (cases) and mothers of survived neonates (controls) is considered minimal.

The study also has some limitations. The first is the study's small sample size might not give the power needed to detect associations between the physical and psychological IPVP with neonatal survival and thus might limit its generalizability. Responses for some stigmatizing information such as women's alcohol consumption habits during index pregnancy and their exposure to sexual violence might incorporate a social desirability bias leading to possible underestimation of the association. Although securing of confidentiality was verily secured and involvement of female data collectors, the very sensitivity nature of the aforementioned information is believed to incorporate the bias in our study.

Although additional research is clearly needed on this topic, our findings have implications for public health programs and for future research. The current efforts to prevent violence against women in Ethiopia are at a very early stage and protection of pregnant

Page $10 / 16$ 
women against such violence has remained largely outside the agenda of violence prevention and child health programs. Our findings give conclusive evidence on risk of violence perpetrated against pregnant women on the survival of their newborns and believed to contribute as impetus for early violence intervention to this vulnerable population.

\section{Conclusion}

Sexual IPV during pregnancy and controlling behaviors of husband/partner significantly and positively associated with neonatal mortality. More efforts are needed towards integrating IPV information in the maternal and child health (MCH) programs of the country in order to improve the overall well-being of both mothers and children. It is imperative that men would be encouraged to participate in the $\mathrm{MCH}$ programs and counseled on safe motherhood in order to promote pregnant women's sexual autonomy and reduce sexual violence. We recommend future large scale and longitudinal studies that would warrant the association between the different forms of IPV during pregnancy and neonatal mortality and better inform the mechanisms through which IPVP affect neonatal survival.

\section{Abbreviations}

Cl: Confidence Interval

CSA: Central Statistical Authority

HDSS: Health and Demographic Surveillance System

EDD: Expected Delivery Date

HH: Household

IPV: Intimate Partner Violence

IPVP: Intimate Partner Violence in/during Pregnancy

$\mathrm{MCH}:$ Maternal and Child Health

OR: Odds Ratio

WHO: World Health Organization

\section{Declarations}

\section{Competing interest}

The authors declare that they have no conflict of interest

\section{Author's contributions}

All authors made substantial contributions to conception and design, acquisition of data, or analysis and interpretation of data; took part in drafting the article or revising it critically for important intellectual content; gave final approval of the version to be published; and agree to be accountable for all aspects of the work.

\section{Acknowledgments}

The authors would like to thank Haramaya University and the African Population and Health Research Center (APHRC) for their support of the study. Authors also wish to thank the study participants, data collectors, and staff of the school of Public Health, College of Health and Medical Sciences for their kind cooperation.

\section{Consent for publications}


We hereby transfer(s), assign(s), or otherwise convey(s) all copyright ownership, including all rights incidental there to, exclusively to Journal of BMC International Health and Human Rights in the event that such work is published by the Journal.

BMC International Health and Human Rights owns the work including:

1. Copyright

2. The right to grant permission to republish the article in whole or in part, with or without fee

3. The right to copy, distributes, and displays the work;

4. The right to produce preprints or reprints and translate in to language other than English for sale or free distribution; and

5. The right to republish the work in a collection of articles in any other mechanical or electronic format

We give the rights to the corresponding author to make necessary changes as per the request of the journal, do the rest of the correspondence on our behalf and he will act as the guarantor for the manuscript on our behalf.

\section{Availability of data and materials}

All the necessary data supporting our findings are contained within the manuscript.

\section{Funding}

There is no funding to undertake this study

\section{Ethical approval and consent to participate}

The Institutional Health Research Ethics Review Committee (IHRERC) of Haramaya University, College of Health and Medical Sciences ethically cleared the study(IHRERC/153/2017, dated October 26/2017). Written informed consent was sought from each participant as recommended in the WHO ethical safety guidelines. In the consent form, participants were informed about the aim of the study, the rights to participate or withdraw. They were also assured of the confidentiality of information.

\section{References}

1. World-Health-Organization: Preventing intimate partner and sexual violence against women: taking action and generating evidence. World Health Organization (WHO). Geneva. 2010.

2. Garcia-Moreno C, Zimmerman C, Morris-Gehring A, Heise L, Amin A, Abrahams N, Montoya O, Bhate-Deosthali P, Kilonzo N, Watts C: Addressing violence against women: a call to action. The Lancet 2015, 385(9978):1685-1695.

3. Dillon G, Hussain R, Loxton D, Rahman S: Mental and physical health and intimate partner violence against women: A review of the literature. International journal of family medicine 2013, 2013.

4. Alhusen JL, Ray E, Sharps P, Bullock L: Intimate partner violence during pregnancy: maternal and neonatal outcomes. Journal of women's health 2015, 24(1):100-106.

5. Shamu S, Abrahams N, Temmerman M, Musekiwa A, Zarowsky C: A systematic review of African studies on intimate partner violence against pregnant women: prevalence and risk factors. PLOS ONE 2011, 6(3):e17591 .

6. Alebel A, Kibret GD, Wagnew F, Tesema C, Ferede A, Petrucka P, Bobo FT, Birhanu MY, Tadesse AA, Eshetie S: Intimate partner violence and associated factors among pregnant women in Ethiopia: a systematic review and meta-analysis. Reproductive health 2018, 15(1):196.

7. CSA: (Central Statistical Agency)[Ethiopia] and ICF : Ethiopia demographic and health survey 2016. Addis Ababa, Ethiopia, and Rockville, Maryland, USA: CSA and ICF 2016.

8. Gurmu E, Endale S: Wife beating refusal among women of reproductive age in urban and rural Ethiopia. BMC international health and human rights 2017, 17(1):6. 
9. Allen M, Raghallaigh MN: Domestic violence in a developing context: the perspectives of women in Northern Ethiopia. Affilia 2013, 28(3):256-272.

10. Hug L, Alexander M, You D, Alkema L, for Child Ul-aG: National, regional, and global levels and trends in neonatal mortality between 1990 and 2017, with scenario-based projections to 2030: a systematic analysis. The Lancet Global Health 2019, 7(6):e710-e720.

11. You D, Hug L, Ejdemyr S, Beise J: Levels and trends in child mortality. Estimates developed by the UN Inter-agency Group for Child Mortality Estimation (IGME). Report 2015. 2015.

12. FMOH: Health Sector Transformation Plan (2015/16-2019/20). Federal Democratic Republic of Ethiopia Ministry of Health. Addis Ababa (Ethiopia); 2015.

13. Pool MS, Otupiri E, Owusu-Dabo E, De Jonge A, Agyemang C: Physical violence during pregnancy and pregnancy outcomes in Ghana. BMC pregnancy and childbirth 2014, 14(1):71.

14. Viellas EF, Gama SGNd, Carvalho MrLd, Pinto LW: Factors associated with physical aggression in pregnant women and adverse outcomes for the newborn. Jornal de pediatria 2013, 89(1):83-90.

15. Marabotti Costa Leite F, Garcia F, Alves de Freitas P, Bravim LR, Canicali Primo C, de Fatima Almeida Lima E: The Consequences of Violence During Pregnancy for Both Fetus and Newborn: Systematic Review. Revista de Pesquisa: Cuidado e Fundamental 2019, 11(2).

16. Memiah P, Opanga Y, Bond T, Cook C, Mwangi M, Fried J, Joseph MA, Owuor K, Mochache V, Machira YW: Is sexual autonomy a protective factor for neonatal, child, and infant mortality? A multi-country analysis. PLOS ONE 2019, 14(2):e0212413.

17. Malta LA, McDonald SW, Hegadoren KM, Weller CA, Tough SC: Influence of interpersonal violence on maternal anxiety, depression, stress and parenting morale in the early postpartum: a community based pregnancy cohort study. BMC pregnancy and childbirth 2012, 12(1):153.

18. Ferraro AA, Rohde LA, Polanczyk GV, Argeu A, Miguel EC, Grisi SJFE, Fleitlich-Bilyk B: The specific and combined role of domestic violence and mental health disorders during pregnancy on new-born health. BMC pregnancy and childbirth 2017, 17(1):257.

19. Baqui A, Williams EK, Rosecrans AM, Agrawal PK, Ahmed S, Darmstadt GL, Kumar V, Kiran U, Panwar D, Ahuja RC: Impact of an integrated nutrition and health programme on neonatal mortality in rural northern India. Bulletin of the World Health Organization 2008, 86:796-804A.

20. Altarac M, Strobino D: Abuse during pregnancy and stress because of abuse during pregnancy and birthweight. JAMWA 2002, 57(4):208-214.

21. Levendosky AA, Bogat GA, Bernard N, Garcia A: The effects of intimate partner violence on the early caregiving system. In Motherhood in the Face of Trauma. Springer; 2018:39-54.

22. Onwuanaku CA, Okolo SN, Ige KO, Okpe SE, Toma BO: The effects of birth weight and gender on neonatal mortality in north central Nigeria. BMC research notes 2011, 4(1):562.

23. Lawn J, Kerber K, Enweronuâ€囚Laryea C, Massee Bateman O: Newborn survival in low resource settings-are we delivering? BJOG: An International Journal of Obstetrics \& Gynaecology 2009, 116:49-59.

24. Musa A, Chojenta C, Geleto A, Loxton D: The associations between intimate partner violence and maternal health care service utilization: a systematic review and meta-analysis. BMC women's health 2019, 19(1):36.

25. Coker AL, Sanderson M, Dong B: Partner violence during pregnancy and risk of adverse pregnancy outcomes. Paediatric and Perinatal Epidemiology 2004, 18(4):260-269.

26. World-Health-Organization: Global and regional estimates of violence against women: prevalence and health effects of intimate partner violence and non-partner sexual violence. World-Health-Organization. Geneva: World Health Organization; 2013.

27. Mosley WH, Chen LC: An analythical framework for the study of child survival in developing countries. Bulletin of the World Health Organization 2003, 81:140-145.

28. Kidus F, Woldemichael K, Hiko D: Predictors of neonatal mortality in Assosa zone, Western Ethiopia: a matched case control study. BMC pregnancy and childbirth 2019, 19(1):108.

29. Mekonnen Y, Tensou B, Telake DS, Degefie T, Bekele A: Neonatal mortality in Ethiopia: trends and determinants. BMC Public Health 2013, 13(1):483. 
30. Yaya Y, Eide KT, Norheim OF, Lindtjom B: Maternal and neonatal mortality in south-west Ethiopia: estimates and socio-economic inequality. PLOS ONE 2014, 9(4):e96294.

31. Yirgu R, Molla M, Sibley L: Determinants of neonatal mortality in rural Northern Ethiopia: A population based nested case control study. PLOS ONE 2017, 12(4):e0172875.

32. Kolola T, Ekubay M, Tesfa E, Morka W: Determinants of neonatal mortality in North Shoa Zone, Amhara regional state, Ethiopia. PLOS ONE 2016, 11(10):e0164472.

33. Wakgari N, Wencheko E: Risk factors of neonatal mortality in Ethiopia. Ethiopian Journal of Health Development 2013, 27(3):192-199.

34. Samuel D, Zinabu D, Alemu B: Magnitude of Neonatal Mortality and associated factors among Neonates at Arba Minch General Hospital. Asploro Journal of Pediatrics and Child Health 2019, 2019(1):20.

35. Mengesha HG, Wuneh AD, Lerebo WT, Tekle TH: Survival of neonates and predictors of their mortality in Tigray region, Northern Ethiopia: prospective cohort study. BMC pregnancy and childbirth 2016, 16(1):202.

36. Demisse AG, Alemu F, Gizaw MA, Tigabu Z: Patterns of admission and factors associated with neonatal mortality among neonates admitted to the neonatal intensive care unit of University of Gondar Hospital, Northwest Ethiopia. Pediatric health, medicine and therapeutics 2017, 8:57.

37. Pastor-Moreno G, Ruiz-PÃ@rez I, Henares-Montiel Js, Petrova D: Intimate partner violence during pregnancy and risk of fetal and neonatal death: a meta-analysis with socioeconomic context indicators. American journal of obstetrics and gynecology 2020 , 222(2):123-133. e125.

38. Memiah P, Bond T, Opanga Y, Kingori C, Cook C, Mwangi M, Gitahi-Kamau N, Mubangizi D, Owuor K: Neonatal, infant, and child mortality among women exposed to intimate partner violence in East Africa: a multi-country analysis. BMC women's health 2020, 20(1):10.

39. Haile D, Lakew Y: Khat chewing practice and associated factors among adults in Ethiopia: further analysis using the 2011 demographic and health survey. PLOS ONE 2015, 10(6):e0130460.

40. Ibrahim Z, Sayed Ahmed W, El-Hamid S, Hagras A: Intimate partner violence among Egyptian pregnant women: incidence, risk factors, and adverse maternal and fetal outcomes. Clin Exp Obstet Gynecol 2015, 42(2):212-219.

41. Dupont WD: Power calculations for matched case-control studies. Biometrics 1988:1157-1168.

42. Assefa N, Berhane Y, Worku A: Pregnancy rates and pregnancy loss in Eastern Ethiopia. Acta obstetricia et gynecologica Scandinavica 2013, 92(6):642-647.

43. Ashenafi W, Mengistie B, Egata G, Berhane Y: Prevalence and Associated Factors of Intimate Partner Violence During Pregnancy in Eastern Ethiopia. International journal of women's health 2020, 12:339-358.

44. World-Health-Organization: WHO Multi-Country Study on Women's Health and Domestic Violence Against Women: Initial Results on Prevalence, Health Outcomes and Women's Responses. 2005.

45. Jansen HA, Watts C, Ellsberg M, Heise L, Garcia-Moreno C: Interviewer training in the WHO multi-country study on women's health and domestic violence. Violence against women 2004, 10(7):831-849.

46. Ellsberg M, Heise L: Researching Violence Against Women. A Practical Guide for Researchers and Activists. In by World Health Organization (WHO), Geneva See also: www path org/files/GBV_rvaw_complete pdf Marie-France Hirigoyen, 2006: Warum tust du mir das an? Gewalt in Partnerschaften: 2005. Citeseer; 2005.

47. World-Health-Organization: (WHO) Putting women first: Ethical and safety recommendations for research on domestic violence against women. Geneva: World Health Organization; 2001.

48. Van Lente E, Barry MM, Molcho M, Morgan K, Watson D, Harrington J, McGee H: Measuring population mental health and social well-being. International journal of public health 2012, 57(2):421-430.

49. Abiola T, Udofia O, Zakari M: Psychometric properties of the 3-item oslo social support scale among clinical students of Bayero University Kano, Nigeria. Malaysian Journal of Psychiatry 2013, 22(2):32-41.

50. Boen H, Dalgard OS, Bjertness E: The importance of social support in the associations between psychological distress and somatic health problems and socio-economic factors among older adults living at home: a cross sectional study. BMC geriatrics 2012, 12(1):27. 
51. Romero-Gutierrez G, Cruz-Arvizu VH, Regalado-Cedillo CA, de Leon ALP-P: Prevalence of violence against pregnant women and associated maternal and neonatal complications in Leon, Mexico. Midwifery 2011, 27(5):750-753.

52. Ahmed S, Koenig MA, Stephenson R: Effects of domestic violence on perinatal and early-childhood mortality: evidence from north India. American Journal of Public Health 2006, 96(8):1423-1428.

53. Bailey BA, Sokol RJ: Prenatal alcohol exposure and miscarriage, stillbirth, preterm delivery, and sudden infant death syndrome. Alcohol Research \& Health 2011, 34(1):86.

54. CSA: Central Statistical Agency)[Ethiopia] and ICF : Ethiopia demographic and health survey 2011. Addis Ababa, Ethiopia, and Rockville, Maryland, USA: CSA and ICF 2012.

55. Rakesh P, Faizal S, Renjini B, Sheeja A, Subhagan S, Salila K: Causes and risk factors for neonatal mortality-a community based case control study from Kollam Kerala. Indian Journal of Maternal and Child Health 2014, 16(1):1-13.

56. Varghese S, Prasad J, Jacob K: Domestic violence as a risk factor for infant and child mortality: a community-based casecontrol study from southern India. National medical journal of India 2013, 26(3):142-146.

57. Henriksen L, Schei B, Vangen S, Lukasse M: Sexual violence and neonatal outcomes: a Norwegian population-based cohort study. BMJ open 2014, 4(10):e005935.

58. Marchant T, Willey B, Katz J, Clarke Sn, Kariuki S, Ter Kuile F, Lusingu J, Ndyomugyenyi R, Schmiegelow C, Watson-Jones D: Neonatal mortality risk associated with preterm birth in East Africa, adjusted by weight for gestational age: individual participant level meta-analysis. PLoS medicine 2012, 9(8):e1001292.

59. Rico E, Fenn B, Abramsky T, Watts C: Associations between maternal experiences of intimate partner violence and child nutrition and mortality: findings from Demographic and Health Surveys in Egypt, Honduras, Kenya, Malawi and Rwanda. Journal of Epidemiology \& Community Health 2011, 65(4):360-367.

60. Rao N, Norris Turner A, Harrington B, Nampandeni P, Banda V, Norris A: Correlations between intimate partner violence and spontaneous abortion, stillbirth, and neonatal death in rural Malawi. International Journal of Gynecology \& Obstetrics 2017, 138(1):74-78.

61. Arunda M, Emmelin A, Asamoah BO: Effectiveness of antenatal care services in reducing neonatal mortality in Kenya: analysis of national survey data. Global Health Action 2017, 10(1):1328796.

62. Lambon-Quayefio MP, Owoo NS: Examining the influence of antenatal care visits and skilled delivery on neonatal deaths in Ghana. Applied health economics and health policy 2014, 12(5):511-522.

63. Lawn JE, Cousens S, Zupan J, Team LNSS: 4 million neonatal deaths: when? Where? Why? The Lancet 2005, 365(9462):891900.

64. Rush D: Maternal nutrition and perinatal survival. Nutrition reviews 2001, 59(10):315-326.

65. Fantahun M, Berhane Y, Wall S, Byass $P, H A ̃$ gberg U: Women's involvement in household decision-making and strengthening social capital: crucial factors for child survival in Ethiopia. Acta paediatrica 2007, 96(4):582-589.

66. Hossain B: Women empowerment and infant mortality in Bangladesh. Applied Economics 2015, 47(51):5534-5547.

\section{Figures}



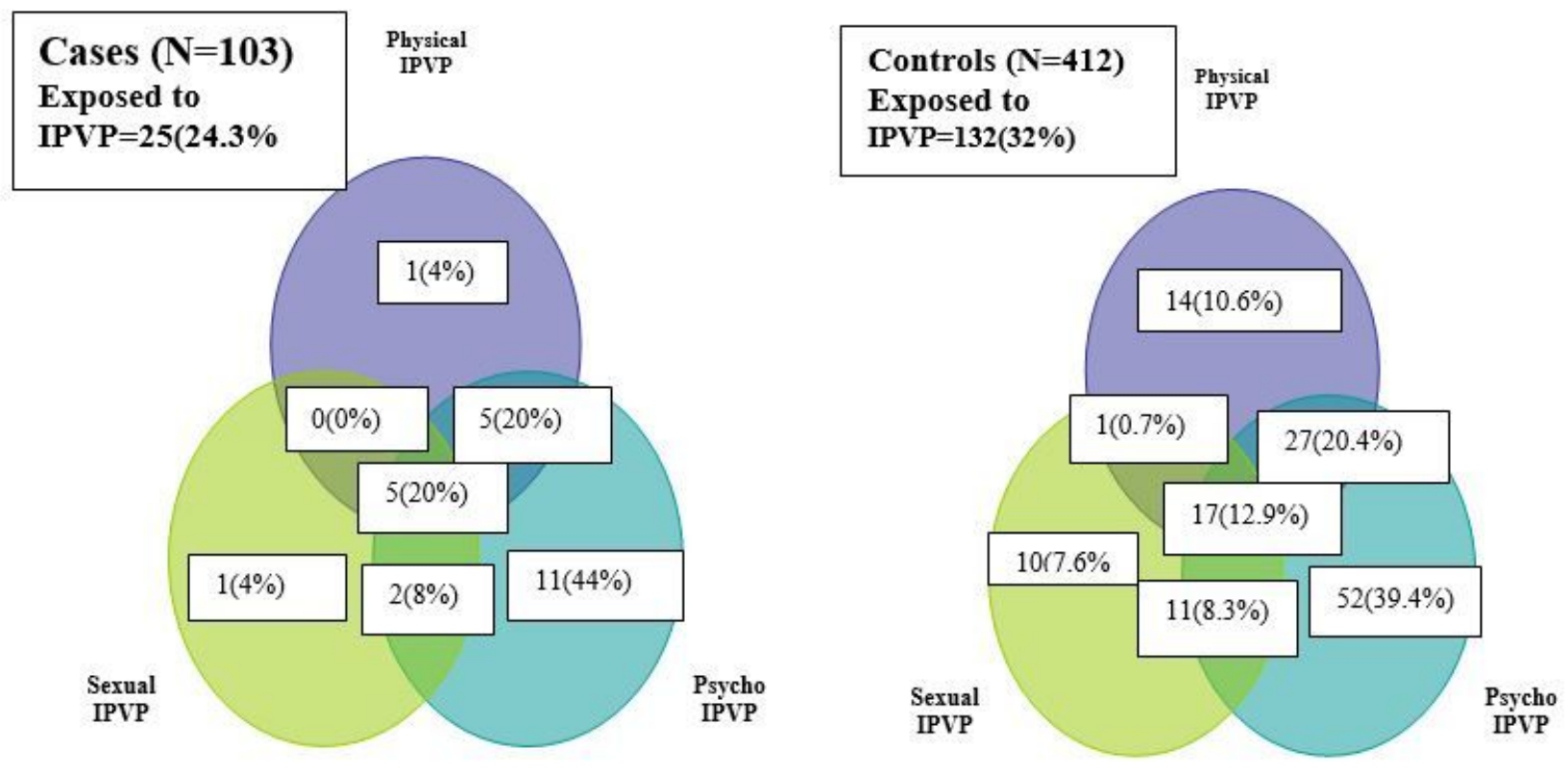

\section{Figure 1}

Venn-diagrams illustrating the experiences of different types of IPVP among Cases and Controls in Eastern Ethiopia, 2018 